\title{
Is Handgrip Strength a Useful Measure to Evaluate Lower Limb Strength and Functional Performance in Older Women?
}

This article was published in the following Dove Press journal:

Clinical Interventions in Aging

\author{
Andre Luiz Felix \\ Rodacki (iD)' \\ Natália Boneti Moreira (iD) 2 \\ Arthur Pitta (D) \\ Renata Wolf (D) \\ Jarbas Melo Filho iD \\ Cintia de Lourdes Nahhas \\ Rodacki iD 1,3 \\ Gleber Pereira (iD) \\ 'Department of Physical Education, \\ Federal University of Parana, Curitiba, \\ Brazil; ${ }^{2}$ Department of Physiotherapy \\ Prevention and Rehabilitation, Federal \\ University of Parana, Curitiba, Brazil; \\ ${ }^{3}$ Department of Physical Education, \\ Paraná Technological Federal University, \\ Paraná, Curitiba, Brazil
}

\begin{abstract}
Aim: This study aimed to determine the association of handgrip strength with isometric and isokinetic strength (hip, knee and ankle extensor/flexor muscles), and functional capacity in older women.

Methods: The handgrip strength and lower limb strength of 199 older women (60-86 years) were measured using JAMAR and BIODEX dynamometers, respectively. Time Up and Go, Five-times-sit-to-stand and 6m-walk functional tests were evaluated. Pearson correlations were used to determine the relationship between variables. Regression analysis was applied to identify if HS was able to predict TUG performance. The effect of age was analyzed by splitting the participants in a group of older women (OLD; from 60 to 70 years old) and very old women (from 71 to 86 years old).
\end{abstract}

Results: The HS and isometric/isokinetic strength correlations were negligible/low and, in most cases, were non-significant. The correlation between handgrip strength and functional tests also ranged predominantly from negligible ( $\mathrm{r}=0.0$ to 0.3 ) to low ( $\mathrm{r}=0.3$ to 0.5 ), irrespective of the group age. The handgrip strength was not able to explain the variance of the TUG performance.

Conclusion: Generalizing handgrip strength as a practical and straightforward measure to determine lower limbs and overall strength, and functional capacity in older women must be viewed with caution. Handgrip strength and standard strength measures of the lower limbs and functional tests present a negligible/low correlation.

Keywords: aged, muscle strength, handgrip, functional capacity

\section{Introduction}

Aging has been related to a decline in muscle mass and strength, which may reduce functional capacity and increase disability, risk of fall and mortality in older adults. ${ }^{1,2}$ These aged-related changes increase the dependence in performing activities of daily living that substantially add to the healthcare costs. ${ }^{3}$ Thus, the assessment of muscle strength in older adults is relevant to determine muscle functioning and its related consequences.

Identifying the best muscle strength assessment in older adults is challenging, as a paramount of measures and protocols have been proposed. However, dynamometric handgrip and knee extension strength measures have predominated in older adult assessments. ${ }^{4}$ Isometric and isokinetic muscle contraction assessments have been preferred to reduce force-velocity influences. Although isokinetic dynamometer is the gold-standard evaluation of strength, its use is limited due to
Correspondence: Andre Luiz Felix Rodacki

Centro de Estudos do Comportamento Motor (CECOM), Universidade Federa do Paraná. Centro Politécnico, Jardim

Botânico, Curitiba, PR, Brasil

TellFax +55 04I 3360-4322

Email rodacki@ufpr.br 
portability and costs. Therefore, muscle strength assessments have often been limited to the use of handgrip strength (HS) measure (ie, via handheld devices), which is reported to present good reproducibility, ${ }^{5}$ inter-rater repeatability ${ }^{6}$ and validity. ${ }^{7}$

Several studies have concluded that HS is a representative measure of overall body strength $^{8,9}$ that predicts essential clinical outcomes, ${ }^{10-13}$ although a number of issues are still unclear. For instance, HS measure is restricted to the upper segment muscles, which may not directly represent the strength status of the lower limbs. It seems mandatory to determine the strength of the lower limbs when predictions are related to functional capacity and risk of falling rather than measuring strength in dissociated sites. Besides, the validity of the HS test is underexplored, since most studies have focused on the relationship between the HS and the isometric/isokinetic strength of knee flexor/extensor muscles. ${ }^{14-16}$ There is a paucity of studies correlating the HS with the strength of the ankle and hip joints, as they are also related to functional capacity and risk of falls. ${ }^{17}$ Furthermore, most studies have included a reduced number of participants, ranging from $20^{14,16}$ to $39^{17}$ older adults, which is a significant methodological limitation.

Handgrip strength and isometric strength of the knee extensor muscles are highly correlated $(r=0.91) ;{ }^{16}$ however, isometric measurements are poor predictors of dynamic performance. ${ }^{18}$ Isometric tests are little specific when considering functional tests, as they encompass dynamic demands. The HS has been proposed as a valid measurement based on its correlation with dynamic lower limb strength measured by functional tests (eg, Time Up and Go and Timed walk tests), presenting moderate to high coefficients (ranging from 0.63 to 0.94$){ }^{7}$ However, conclusions must be viewed with caution since they assessed a limited number of participants $(n=10)$.

The participants' age is an additional aspect that has been relatively neglected in the literature. Older adults are expected to experience less pronounced HS and functional performance effects in comparison to very old counterparts, as age significantly impacts on strength. It has been recently demonstrated that HS predicts falls among young and older adults (from 60 to 79 years old), whereas, it fails to identify fall prevalence in very old adults (eg, $\geq 80$ years old). ${ }^{19}$ Thus, it is not known whether the relationship between HS and the isometric/isokinetic strength among old and very old adults is influenced to the same extent.

Therefore, this study was designed to determine: i) the association between HS and the isometric and isokinetic strength of the lower limb joints in older women; ii) the association between HS and functional capacity in older women; and iii) whether the relationships between HS and isometric and isokinetic strength, and functional capacity are influenced by age. These results are of interest for those involved in epidemiological studies regarding strength and functional capacity measurements, especially those that rely on HS to determine clinical outcomes in old and very old adults. It was hypothesized that HS and the performance of isometric and isokinetic will present small correlations. It was also hypothesized that HS and functional capacity are not correlated and that HS measures are unable to explain functional capacity. Finally, it was the expected age to influence the strength of the correlations between HS and isometric and isokinetic strength and functional performance. These results are also of clinical interest as a large number of intervention protocols, patient classifications, and outcome assessments involving the lower limbs are based on HS measurements.

\section{Methods}

\section{Participants and Participants' Involvement}

The data for this cross-sectional study were obtained between 2016 and 2018 from older women recruited from the local community (via flyers, folders and social networks) in Curitiba, Brazil, a city of 197,965 individuals aged 60 or older. Sample size was calculated using the Epi info calculator developed by Center of Disease Control and Prevention ${ }^{20}$ using the following parameters: (i) the population of older adults from Curitiba; (ii) $80 \%$ confidence level; (iii) sampling error of 5\%; (iv) $50 \%$ of anticipated frequency, considering the maximum variance; and (v) 10\% margin for possible losses and refusals. Therefore, the initial sample size estimated was 182 older adults.

Thus, our data were obtained from participants involved in five different studies, previously performed in the same laboratory that has included HS, isometric/isokinetic and functional capacity tests. Data collection was conducted by trained researchers, with at least three years of experience, who attended a training program designed to standardize all procedures and measurements performed in each study. Although participants were recruited from different studies based on the following inclusion criteria: 60 years or older, did not suffer from cognitive or medical problems that limited their ability to perform the tests and were able to conclude all procedures. The individuals did not participate in any training program and lived independently. All 
participants responded to the validated and adapted Portuguese version of the Mini Mental test $\mathrm{t}^{21}$ and were deemed as able to understand all instructions and demands involved in the experiments in all studies. The exclusion criteria were as follows: individuals with unstable cardiovascular disease, acute infections and tumors, with knee or hip prostheses. The data from 199 older women were analyzed; however, not all participants were involved in all tests as some studies had different purposes. The number of participants in each test is reported accordingly. The effect of age was verified by dividing the sample into two halves (using the median as a criterion) to obtain a group of old (OLD, from 60 to 70 years-old, $\mathrm{n}=97 ; 66.15 \pm 2.19$ yearsold; $1.57 \pm 0.07 \mathrm{~m} ; 68.1 \pm 13.0 \mathrm{~kg}$ ) and very old adults (VOD, from 71 to 86 years-old, $\mathrm{n}=107 ; 74.26 \pm 4.21$; $1.56 \pm 0.07 \mathrm{~m} ; 69.8 \pm 12.4 \mathrm{~kg}$ ). The data of all participants are also provided (ALL). The University Ethics Committee approved the procedures of all experiments and all participants gave written consent to participate in each study.

\section{Instruments and Procedures}

\section{Muscle Strength}

As a general rule, the assessments ranged from one to three sessions and followed identical procedures. Participants went through a preliminary face-to-face interview to collect personal and anthropometric data. The HS was assessed in the first session $\left(\right.$ Jamar $^{\circledR}$ dynamometer), while the other assessments were conducted in the remaining sessions. The HS measure was assessed in the dominant hand and, while the individuals were seated in an upward position with the elbow in $90^{\circ}$ of flexion. ${ }^{22}$ The average obtained from three trials was used for analysis purposes. The Jamar hand dynamometer is the most widely used instrument to evaluate HS, presenting $0.5 \mathrm{~kg}$ of accuracy and high level of test-retest, inter-rater and intra-rater reliability to older adults $(\mathrm{ICC} \geq 0.85){ }^{23}$

The isometric tests of the lower limbs (ankle, knee and hip joints) were followed by the isokinetic dynamic tests, which are considered as the gold-standard for muscle strength assessments [Liberatori 24], at two speeds $\left(60^{\circ} . \mathrm{s}^{-1}\right.$ and $\left.180^{\circ} . \mathrm{s}^{-1}\right)$ (Biodex Medical Systems, Inc. Shirley, NY, USA). The joint angle for the isometric test of the knee joint was set at $60^{\circ}$, the hip joint at $105^{\circ}$ and the ankle joint in a neutral position, according to the manufacturer guidelines. ${ }^{25}$ During the isometric test, the dynamometer maintains zero velocity at any selected point in the range of motion in such a way that changes in joint angle and overall muscle length do not occur.
Joint and speed were randomly tested with an interval of 3-5 min imposed between trials. Prior testing, a period of familiarization for the HS and isometric/isokinetic tests was allowed, which included 3-5 repetitions to minimize learning effects. Familiarization was discontinued when differences between the last two measurements were smaller than $5 \%$. The intraclass correlation coefficients of isokinetic test-retest are high (hip flexion $\geq 0.89$; hip extension $\geq 0.88$; knee flexion $\geq 0.94$ and knee extension $\geq 0.88$ and dorsiflexion $\geq 0.8)^{26,27}$

\section{Functional Capacity}

The functional tests were generally performed in the last session and included the Time Up and Go (TUG, walking $3 \mathrm{~m}$ around a cone and returning to a seated position at their normal gait speed), ${ }^{25}$ the Five-times-sit-to-stand test (5STS, five times sit to stand test from an armless chair and having both hands crossed against the chest) ${ }^{28}$ and the $6 \mathrm{~m}$-walk test (W6M). ${ }^{29}$ Reliability and validity have been reported as high to moderate in older adults, from 0.75 to 0.99 in the $\mathrm{TUG}^{30}{ }^{30}$ from 0.63 to $0.95^{31}$ in the $5 \mathrm{STS}{ }^{7}$ and from 0.52 to 0.95 in the $\mathrm{W}_{6} \mathrm{M}^{30} \mathrm{~A}$ comprehensive description of these tests can be found elsewhere. ${ }^{25,28,29}$

\section{Statistical Analyses}

Descriptive statistics were presented as means $\pm \mathrm{SD}$ and comparisons between age groups were performed using unpaired t-tests. The Pearson correlation coefficient was calculated to determine the HS relationship with isometric and isokinetic strength and functional capacity. The correlation coefficients between 0 and 0.3 were considered negligible; $>0.3$ and 0.5 , low; $>0.5$ and 0.7 , moderate, $>0.7$ and 0.9 , high; $>0.9$ and 1.0 , very high. ${ }^{32}$ The Benjamini-Hochberg procedure ${ }^{33}$ was applied to reduce the false discovery rate and the $p$ values refer to the adjusted $\mathrm{p}$ values. In addition, Effect size (ES), Power and Minimal Detectable Change (MDC) were calculated.

A multiple linear regression analysis was performed having the TUG (a functional measure) as the dependent variable and the strength measures as the dependent variables. The TUG was selected as a dependent variable as it has been described as one of the most representative functional measures. The isometric and the hip isokinetic measures were not included because the reduced number of data (missing values) would compromise the power of the analysis. Therefore, the HS and the isokinetic measures of the ankle and knee joints at $60^{\circ} . \mathrm{s}^{-1}$ and $180 . \mathrm{s}^{-1}$ were included in the multiple linear regression analysis using 
a "forced entry" approach. The multiple linear regression was performed separately for all participants (ALL) and for each group (OLD and VOD) to determine the contribution of each dependent variable in the regression model. All statistical tests were performed with the Wizard Pro Software (version 1.9.21). The significance level to the was set at $\mathrm{p}<0.05$.

\section{Results}

The results indicated that HS of the VOD was $8.5 \%$ lower than the OLD group (n.s; $\mathrm{p}=0.07$ ). There were no differences between groups in the ankle and hip muscles, irrespective of the test (isometric, $60^{\circ} . \mathrm{s}^{-1}$ or $180^{\circ} \cdot \mathrm{s}^{-1}$ ). The isometric strength of the knee muscles did not differ between groups. On the other hand, the performance of the knee muscles in the isokinetic tests was lower in the VOD in comparison to the OLD group, especially for the knee flexor muscles, irrespective of the test speed. The 5STS test did not differ between groups. However, the OLD group presented a better performance in the TUG test $(10 \% ; \mathrm{p}<0.02)$. The performance of the VOD was worse than in the OLD group in the W6M test $(15 \%$ slower), although the significance level was borderline $(\mathrm{p}=0.08)$. The HS, lower limb isometric and isokinetic strength and functional tests of both groups are presented in Table 1.

The correlation coefficients between HS and isometric and isokinetic strength of the ankle muscles tested are presented in Figure 1. The HS was positively correlated with the isokinetic strength of the ankle muscles, although the magnitudes ranged from low to moderate. Such correlations revealed that HS explains a small fraction of the variation of the isokinetic torque (ie, $<16 \%$ ), irrespective of the test speed or age.

The HS was positively correlated with the isokinetic strength of the knee muscles (Figure 2); however, in most cases, the correlation coefficients varied from negligible to low $(\mathrm{r}<0.4)$. Therefore, the HS explained a small fraction of the knee strength variance. The largest correlation was found between HS and isometric strength of the knee extensors, which explains approximately $25 \%$ of the HS variance.

The negative association between HS and isokinetic strength of hip muscles was observed, irrespective of the test speed. On the other hand, the isokinetic strength of the hip flexors test showed a non-significant and negligible correlation with the HS (from 0.014 to 0.053 ). The isokinetic strength of the hip flexors at $180^{\circ} . \mathrm{s}^{-1}$ presented a moderate correlation with the HS $(r=0.55 ; \mathrm{p}<0.001)$. The HS and the functional tests presented negligible and non-significant correlations (ie, $<0.13$ ), irrespective of the age group (Figure 2). Age was negatively correlated with HS $(\mathrm{p}<0.05)$. It is interesting to note that age explains less than $10 \%$ of the HS variance in OLD and VOD groups (Table 2).

The linear multiple regression analyses (see Table 3) revealed a low ability of the strength measurements to predict the TUG performance $\left(\mathrm{R}^{2}\right.$ ranging from 0.18 to 0.23 ), irrespective of the age group or isokinetic test speed. The torque of the plantar flexor muscles was the only significant measure to explain TUG performance when the test was set at $60^{\circ} . \mathrm{s}^{-1}$. The plantar flexor torque at $60^{\circ}$. $\mathrm{s}^{-1}$ was significant for ALL, OLD and borderline for the VOD group. The regression equation, including HS and the ankle and knee isokinetic tests performed at $180^{\circ} . \mathrm{s}^{-1}$, indicated a small but significant contribution of the knee flexor muscles peak torque for ALL and VOD groups. It is interesting to note that HS failed to significantly explain TUG performance, irrespective of the age of the participants. The detailed regression models are presented in Table 3.

\section{Discussion}

The HS was similar to the normative data ${ }^{34}$ and corresponded to the percentile 70 in the group aged 60-69 years old (ie, $24.6 \mathrm{~kg}$ ). Small variations between studies may be attributed to several factors such as device calibration, postural variance and functional status. However, the VOD group corresponded to the percentile 90 of the normative data ${ }^{34}$ to the group aged 70 or older (ie, $23.8 \mathrm{~kg}$ ). The statistics did not confirm the existence of significant differences between age groups, as the HS was only $8.5 \%$ smaller in the VOD. However, as expected, HS reduced with age, ${ }^{35}$ which was negatively and poorly correlated with age $(r=-0.23-0.29) .{ }^{3}$ It may be the case that age, as a chronological marker, explains no more than $10.0 \%$ of the HS, whereas overall physical fitness may play a more relevant contribution. Indeed, not all individuals have reduced strength as they age. ${ }^{36}$ It seems that muscle functioning in the upper limbs has a less steep decline than lower limbs muscle groups and a less pronounced difference between age groups may have occurred.

The correlation between HS and lower limb strength ranged from negligible to low and was predominantly nonsignificant. These results are contrasting with others that have reported positive, but low $(r=0.44)^{4}$ and moderate correlations $(r=0.67 ; r=0.67),{ }^{3,37}$ while assessing HS and 
Table I Physical Characteristics, Handgrip Strength, Isometric and Isokinetic Strength of the Ankle, Knee and Hip Flexor, and Extensor Muscles, and Functional Tests of All (ALL), Older (OLD) and Very Old (VOD) Participants

\begin{tabular}{|c|c|c|c|c|c|c|c|}
\hline \multirow[t]{2}{*}{ Physical, Strength and Functional Parameters } & ALL & OLD & VOD & \multirow[t]{2}{*}{$\mathbf{p}^{*}$} & \multirow[t]{2}{*}{ ES } & \multirow[t]{2}{*}{ Power (\%) } & \multirow[t]{2}{*}{ MDC } \\
\hline & $\begin{array}{l}M \pm S D \\
n ;[95 \% \mathrm{Cl}]\end{array}$ & $\begin{array}{l}M \pm S D \\
n ;[95 \% \mathrm{Cl}]\end{array}$ & $\begin{array}{l}M \pm S D \\
n ;[95 \% \mathrm{Cl}]\end{array}$ & & & & \\
\hline Age (years old) & $\begin{array}{l}70.3 \pm 5.3 \\
199 ;[69.6-7 \mid .1]\end{array}$ & $\begin{array}{l}66.1 \pm 2.2 \\
97 ;[65.7-65.5]\end{array}$ & $\begin{array}{l}74.3 \pm 4.2 \\
102 ;[73.5-75.2]\end{array}$ & $\begin{array}{l}\mathrm{N} . \\
\mathrm{A} .\end{array}$ & - & - & - \\
\hline Stature $(\mathrm{m})$ & $\begin{array}{l}1.56 \pm 0.07 \\
199 ;[1.55-1.57]\end{array}$ & $\begin{array}{l}1.56 \pm 0.07 \\
97 ;[1.55-1.58]\end{array}$ & $\begin{array}{l}1.56 \pm 0.07 \\
102 ;[1.55-1.57]\end{array}$ & N.A & - & - & - \\
\hline Body Mass (Kg) & $\begin{array}{l}68.3 \pm 12.0 \\
199 ;[65.6-69.9]\end{array}$ & $\begin{array}{l}69.8 \pm 12.4 \\
97 ;[67.4-72.4]\end{array}$ & $\begin{array}{l}66.7 \pm 11.4 \\
97 ;[64.5-69.0]\end{array}$ & N.A & - & - & - \\
\hline $\begin{array}{l}\text { Body Mass Index } \\
\left(\mathrm{kg} \cdot \mathrm{m}^{-2}\right)\end{array}$ & $\begin{array}{l}27.9 \pm 4.4 \\
199 ;[27.3-28.5]\end{array}$ & $\begin{array}{l}28.5 \pm 4.5 \\
97 ;[27.6-29.4]\end{array}$ & $\begin{array}{l}27.4 \pm 4.2 \\
102 ;[26.6-28.2]\end{array}$ & N.A & - & - & - \\
\hline Handgrip Strength (kgf) & $\begin{array}{l}23.5 \pm 6.0 \\
199 ;[22.7-24.4]\end{array}$ & $\begin{array}{l}24.6 \pm 6.7 \\
97 ;[23.2-25.9]\end{array}$ & $\begin{array}{l}22.5 \pm 5.2 \\
102 ;[21.5-23.6]\end{array}$ & 0.07 & 0.35 & 69.2 & 1.12 \\
\hline Plantarflexor isometric strength (kgf) & $\begin{array}{l}56.2 \pm 19.8 \\
69 ;[5|.5-6| .0]\end{array}$ & $\begin{array}{l}60.5 \pm 21.5 \\
31 ;[52.6-68.4]\end{array}$ & $\begin{array}{l}52.8 \pm 17.9 \\
38 ;[46.9-58.7]\end{array}$ & 0.18 & 0.39 & 35.7 & 6.28 \\
\hline Plantarflexor isokinetic $60^{\circ} . \mathrm{s}^{-1}$ (kgf) & $\begin{array}{l}38.2 \pm 13.5 \\
148 ;[36.0-40.4]\end{array}$ & $\begin{array}{l}39.9 \pm 13.8 \\
72 ;[36.7-43.1]\end{array}$ & $\begin{array}{l}36.6 \pm 13.1 \\
76 ;[33.6-39.6]\end{array}$ & 0.21 & 0.24 & 31.9 & 2.89 \\
\hline Plantarflexor isokinetic $180^{\circ} . \mathrm{s}^{-1}(\mathrm{kgf})$ & $\begin{array}{l}26.3 \pm 10.9 \\
148 ;[24.5-28.1]\end{array}$ & $\begin{array}{l}28.1 \pm 11.8 \\
72 ;[25.3-30.8]\end{array}$ & $\begin{array}{l}24.6 \pm 9.8 \\
76 ;[22.4-26.9]\end{array}$ & 0.13 & 0.32 & 49.9 & 2.37 \\
\hline Dorsiflexor isometric strength (kgf) & $\begin{array}{l}22.8 \pm 5.8 \\
69 ;[21.4-24.2]\end{array}$ & $\begin{array}{l}22.9 \pm 5.4 \\
31 ;[21.0-24.9]\end{array}$ & $\begin{array}{l}22.7 \pm 6.3 \\
38 ;[20.6-24.7]\end{array}$ & 0.85 & 0.03 & 3.5 & 1.84 \\
\hline Dorsiflexor isokinetic $60^{\circ} . \mathrm{s}^{-1}(\mathrm{kgf})$ & $\begin{array}{l}17.3 \pm 3.6 \\
148 ;[16.7-\mid 7.9]\end{array}$ & $\begin{array}{l}17.7 \pm 3.4 \\
72 ;[16.9-18.5]\end{array}$ & $\begin{array}{l}17.0 \pm 3.7 \\
76 ;[16.1-\mid 7.8]\end{array}$ & 0.32 & 0.19 & 22.3 & 0.77 \\
\hline Dorsiflexor isokinetic $180^{\circ} . \mathrm{s}^{-1}(\mathrm{kgf})$ & $\begin{array}{l}15.5 \pm 3.9 \\
148 ;[14.8-\mid 6.1]\end{array}$ & $\begin{array}{l}16.1 \pm 4.0 \\
72 ;[15.4-17.0]\end{array}$ & $\begin{array}{l}14.9 \pm 3.7 \\
76 ;[14 .|-| 5.8]\end{array}$ & 0.15 & 0.31 & 42.3 & 0.84 \\
\hline Knee extensor isometric strength (kgf) & $\begin{array}{l}92.0 \pm 27.3 \\
69 ;[85.4-98.6]\end{array}$ & $\begin{array}{l}96.2 \pm 30.0 \\
31 ;[85.2-107.2]\end{array}$ & $\begin{array}{l}88.6 \pm 24.7 \\
38 ;[80.5-96.7]\end{array}$ & 0.34 & 0.36 & 20.4 & 8.63 \\
\hline Knee extensor isokinetic $60^{\circ} \cdot \mathrm{s}^{-1}(\mathrm{kgf})$ & $\begin{array}{l}82.8 \pm 20.1 \\
199 ;[79.9-85.7]\end{array}$ & $\begin{array}{l}86.3 \pm 20.7 \\
97 ;[82.1-25.9]\end{array}$ & $\begin{array}{l}79.5 \pm 20.7 \\
102 ;[75.4-83.6]\end{array}$ & 0.08 & 0.32 & 63.9 & 3.89 \\
\hline Knee extensor isokinetic $180^{\circ} . \mathrm{s}^{-1}(\mathrm{kgf})$ & $\begin{array}{l}63.1 \pm 19.7 \\
199 ;[60.3-65.8]\end{array}$ & $\begin{array}{l}67.5 \pm 21.4 \\
97 ;[63.1-71.8]\end{array}$ & $\begin{array}{l}58.8 \pm 17.0 \\
102 ;[55.5-62.2]\end{array}$ & 0.01 & 0.45 & 87.3 & 2.99 \\
\hline Knee flexor isometric strength (kgf) & $\begin{array}{l}37.5 \pm 9.8 \\
69 ;[35.1-39.8]\end{array}$ & $\begin{array}{l}39.0 \pm 8.9 \\
31 ;[35.7-42.3]\end{array}$ & $\begin{array}{l}36.2 \pm 10.5 \\
38 ;[32.8-39.7]\end{array}$ & 0.32 & 0.28 & 22.3 & 3.12 \\
\hline Knee flexor isokinetic $60^{\circ} . \mathrm{s}^{-1}(\mathrm{kgf})$ & $\begin{array}{l}40.4 \pm 12.7 \\
199 ;[38.6-42.2]\end{array}$ & $\begin{array}{l}43.2 \pm 12.7 \\
97 ;[40.6-45.7]\end{array}$ & $\begin{array}{l}37.7 \pm 12.2 \\
102 ;[35.4-40.2]\end{array}$ & 0.02 & 0.44 & 87.6 & 2.37 \\
\hline Knee flexor isokinetic $180^{\circ} . \mathrm{s}^{-1}(\mathrm{kgf})$ & $\begin{array}{l}40.4 \pm 12.7 \\
199 ;[38.6-42.2]\end{array}$ & $\begin{array}{l}37.9 \pm 10.7 \\
97 ;[35.7-40.0]\end{array}$ & $\begin{array}{l}33.2 \pm 11.8 \\
102 ;[30.9-35.5]\end{array}$ & 0.02 & 0.41 & 83.8 & 2.14 \\
\hline Hip extensor isokinetic $60^{\circ} . \mathrm{s}^{-1}(\mathrm{kgf})$ & $\begin{array}{l}69.5 \pm 27.3 \\
51 ;[61.8-77.2]\end{array}$ & $\begin{array}{l}70.8 \pm 31.4 \\
25 ;[57.9-83.8]\end{array}$ & $\begin{array}{l}68.3 \pm 23.4 \\
26 ;[58.9-77.8]\end{array}$ & 0.79 & 0.1 & 5.1 & 10.07 \\
\hline Hip extensor isokinetic $180^{\circ} . \mathrm{s}^{-1}(\mathrm{kgf})$ & $\begin{array}{l}43.9 \pm 20.7 \\
5 I ;[38 . I-49.8]\end{array}$ & $\begin{array}{l}46.3 \pm 22.7 \\
25 ;[36.9-55.7]\end{array}$ & $\begin{array}{l}41.7 \pm 18.7 \\
26 ;[34.1-49.2]\end{array}$ & 0.48 & 0.22 & 12.1 & 7.62 \\
\hline
\end{tabular}


Table I (Continued).

\begin{tabular}{|c|c|c|c|c|c|c|c|}
\hline \multirow[t]{2}{*}{ Physical, Strength and Functional Parameters } & ALL & OLD & VOD & \multirow[t]{2}{*}{$\mathbf{p}^{*}$} & \multirow[t]{2}{*}{ ES } & \multirow[t]{2}{*}{ Power (\%) } & \multirow[t]{2}{*}{ MDC } \\
\hline & $\begin{array}{l}M \pm S D \\
n ;[95 \% \mathrm{Cl}]\end{array}$ & $\begin{array}{l}M \pm S D \\
n ;[95 \% \mathrm{Cl}]\end{array}$ & $\begin{array}{l}M \pm S D \\
n ;[95 \% \mathrm{Cl}]\end{array}$ & & & & \\
\hline Hip flexor isokinetic $60^{\circ} . \mathrm{s}^{-1}(\mathrm{kgf})$ & $\begin{array}{l}58.5 \pm 12.1 \\
51 ;[55 .|-6| .9]\end{array}$ & $\begin{array}{l}61.5 \pm 13.1 \\
25 ;[56.1-66.9]\end{array}$ & $\begin{array}{l}55.6 \pm 10.5 \\
26 ;[51.3-59.8]\end{array}$ & 0.15 & 0.49 & 42.5 & 4.45 \\
\hline Hip flexor isokinetic $180^{\circ} . \mathrm{s}^{-1}(\mathrm{kgf})$ & $\begin{array}{l}46.6 \pm 10.7 \\
5 \mathrm{I} ;[43.5-49.7]\end{array}$ & $\begin{array}{l}50.1 \pm 10.8 \\
25 ;[45.6-54.5]\end{array}$ & $\begin{array}{l}43.2 \pm 9.7 \\
26 ;[39.3-47.1]\end{array}$ & 0.13 & 0.67 & 66.9 & 3.95 \\
\hline 5STS (s) & $\begin{array}{l}11.5 \pm 3.42 \\
196 ;[11.0-11.98]\end{array}$ & $\begin{array}{l}\mid 1.1 \pm 3.21 \\
96 ;[10.5-11.8]\end{array}$ & $\begin{array}{l}11.83 \pm 3.6 \\
100 ;[11.1-12.5]\end{array}$ & 0.47 & 0.21 & 32.3 & 0.64 \\
\hline TUG (s) & $\begin{array}{l}9.32 \pm 2.58 \\
198 ;[8.95-9.68]\end{array}$ & $\begin{array}{l}8.63 \pm 1.33 \\
97 ;[8.35-8.89]\end{array}$ & $\begin{array}{l}9.97 \pm 3.23 \\
102 ;[9.33-10.65]\end{array}$ & 0.02 & 0.54 & 97.1 & 0.48 \\
\hline W6M (s) & $\begin{array}{l}7.68 \pm 1.67 \\
199 ;[7.44-7.97]\end{array}$ & $\begin{array}{l}7.30 \pm 1.27 \\
97 ;[7.04-7.55]\end{array}$ & $\begin{array}{l}8.05 \pm 1.91 \\
102 ;[7.62-8.24]\end{array}$ & 0.08 & 0.46 & 90.6 & 0.31 \\
\hline
\end{tabular}

Notes: OLD $=60$ to 70 years old; VOD $=71$ to 86 years old. $\mathrm{p}^{*}=$ adjusted Benjamini-Hochberg Procedure.

Abbreviations: M, mean; S.D., standard deviation; n, number of participants assessed; $95 \% \mathrm{Cl}$, $95 \%$ confidence interval; 5STS, five times sit-to-stand test; TUG, time up and go test; W6M, 6-meter walk test; $p$, significance level; N.A., not applicable; ES, effect size; MDC, minimal detectable change.

knee extensor strength in frail elderly. Norman and colleagues $^{38}$ have reported a high correlation between HS and isometric strength of the knee extensor in cancer patients $(r=0.75)$. Felicio and colleagues ${ }^{39}$ presented negligible to low correlation coefficients ( $\mathrm{r}=0.09$ to 0.26 ) between HS and the knee peak torques $(n=221)$, while others $^{40}$ found only a low correlation $(r=0.43)$. These findings do not endorse that HS can be used as a surrogate
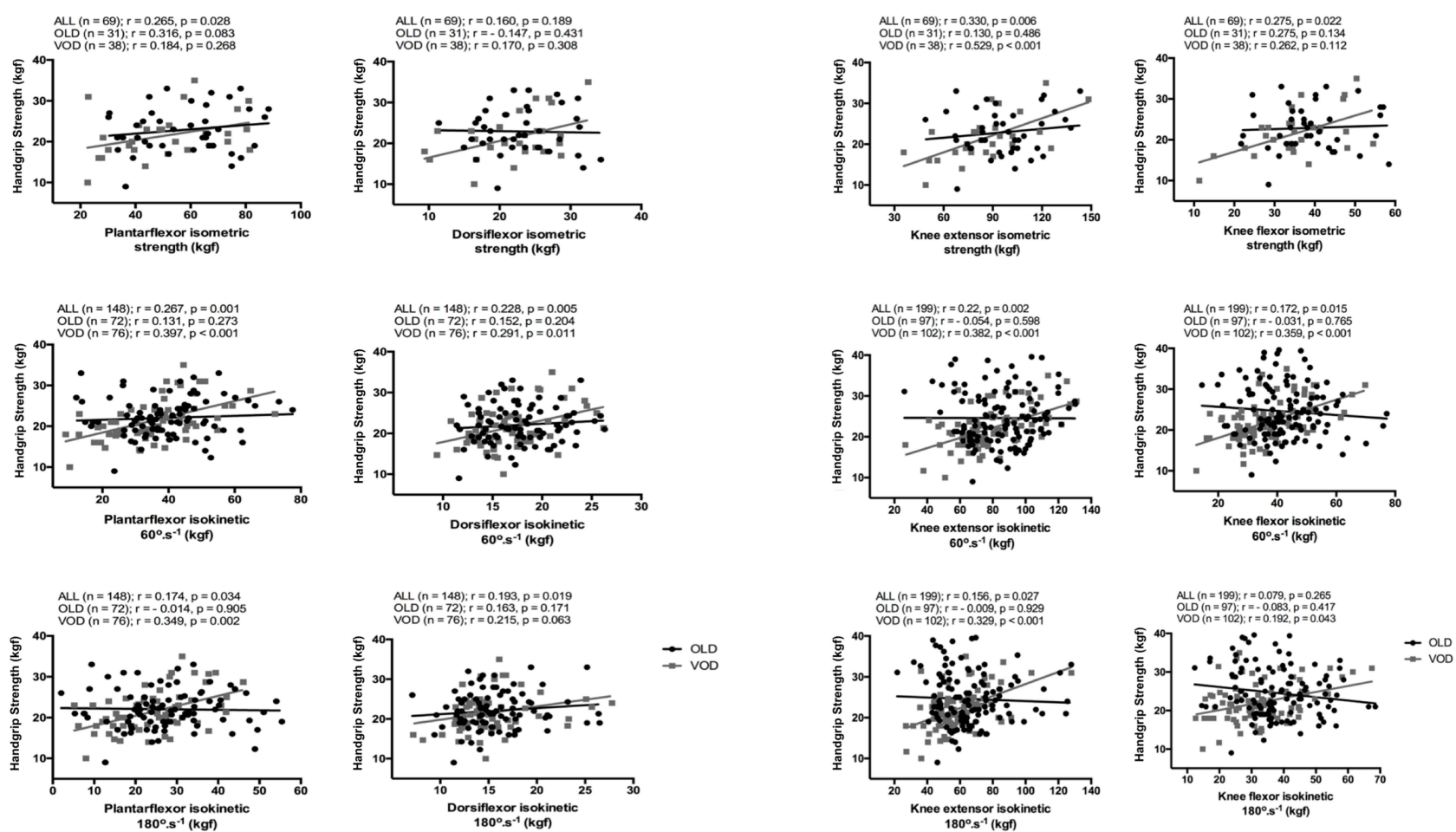

Figure I Handgrip strength correlations with isometric and isokinetic strength at $60^{\circ} . \mathrm{s}^{-1}$ and $180^{\circ} . \mathrm{s}^{-1}$ of the plantar flexor and dorsiflexor muscles (left panel) and of the extensor and flexor muscles of the knee (right panel). Correlation coefficient ( $r$ ) and number of participants ( $n$ ) for all individuals (ALL) and divided by group (OLD: 60-70 years-old; VOD: 7I-86 years-old). 

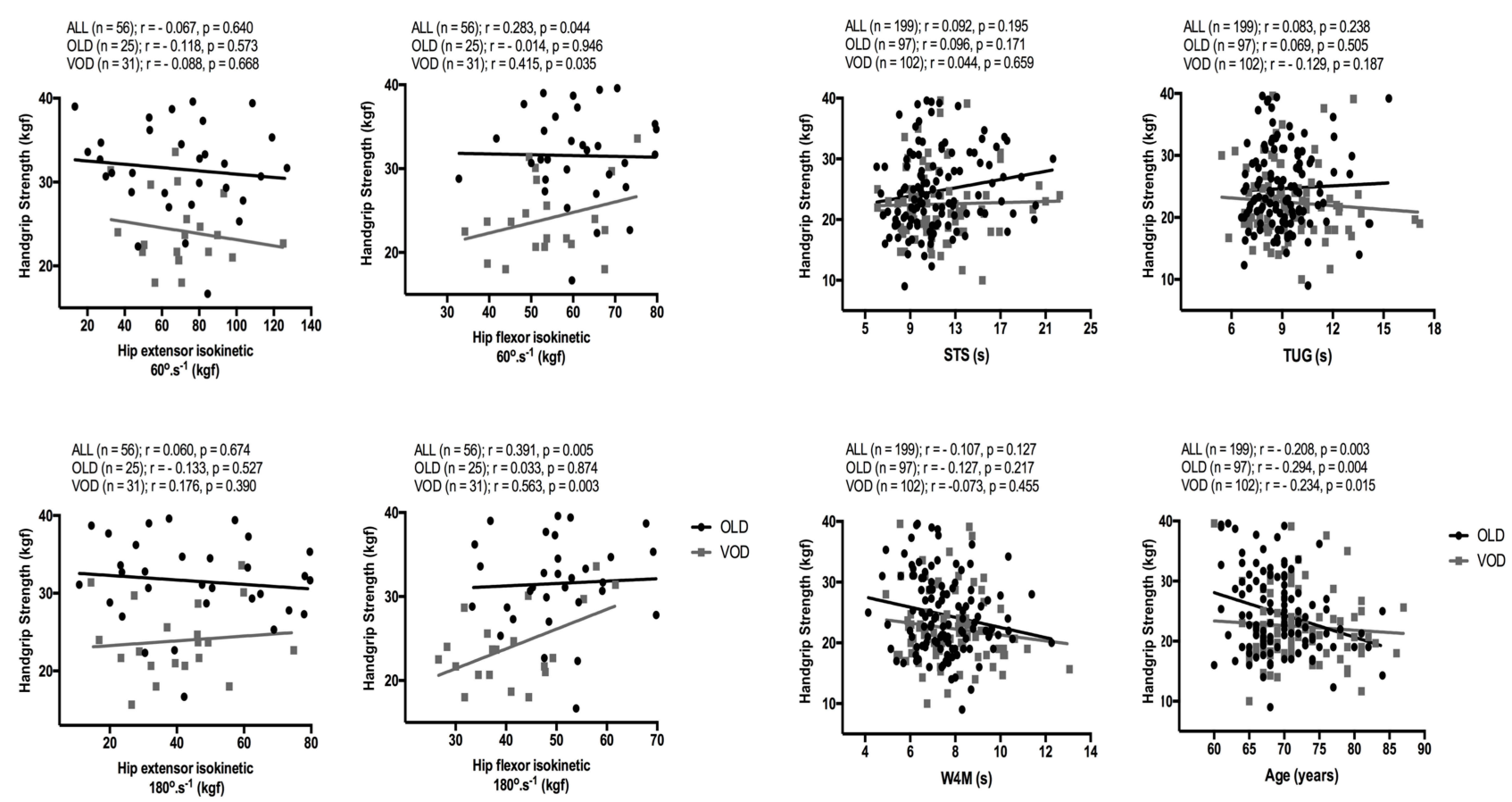

Figure 2 Handgrip strength correlations with isokinetic strength at $60^{\circ} . \mathrm{s}^{-1}$ and $180^{\circ} . \mathrm{s}^{-1}$ of hip extensor and flexor muscles (left panel) and with the functional tests (right panel). Correlation coefficient ( $r$ ) and number of participants $(n)$ for all individuals (ALL) and divided by group (OLD: 60-70 years-old; VOD: 7I-86 years-old).

for quadriceps strength measurements, irrespective of the test speed $\left(60^{\circ} . \mathrm{s}^{-1}\right.$ or $\left.180^{\circ} . \mathrm{s}^{-1}\right)$. The data from the ankle and hip joints for both muscle group pairs (flexors and extensors) also suggest a negligible or low association between HS and isometric or isokinetic strength.
The argument that an unequivocal relationship subsists between HS and lower segment strength, it was not supported in any of the lower limb joints, irrespective of age and test speed. Although a positive correlation has been reported and some advantages are advocated in favor of

Table 2 Correlations of Isometric and Isokinetic Strength at $60^{\circ} . \mathrm{s}^{-1}$ and $180^{\circ} . \mathrm{s}^{-1}$ of Plantar Flexor, Dorsiflexor, Extensor and Flexor Muscles of the Knee and Hip Joints with Functional Tests and Age Groups

\begin{tabular}{|c|c|c|c|c|c|c|}
\hline \multirow[t]{2}{*}{ Isometric and Isokinetic Lower Limb Strength } & \multicolumn{2}{|l|}{ 5STS } & \multicolumn{2}{|l|}{ TUG } & \multicolumn{2}{|l|}{ W6M } \\
\hline & OLD & VOD & OLD & VOD & OLD & VOD \\
\hline Plantarflexor isometric strength & -0.26 & -0.25 & -0.18 & $-0.36^{*}$ & -0.02 & $-0.43 * *$ \\
\hline Plantarflexor isokinetic $60^{\circ} . \mathrm{s}^{-1}$ & $-0.33^{* *}$ & $-0.34 * *$ & $-0.33^{*}$ & $-0.39 * *$ & $-0.23^{*}$ & $-0.53 * *$ \\
\hline Plantarflexor isokinetic $180^{\circ} . \mathrm{s}^{-1}$ & $-0.35^{* *}$ & $-0.32^{* *}$ & -0.23 & $-0.39 * *$ & -0.07 & $-0.37^{* *}$ \\
\hline Dorsiflexor isometric strength & -0.05 & -0.19 & -0.04 & -0.15 & 0.00 & -0.02 \\
\hline Dorsiflexor isokinetic $60^{\circ} . \mathrm{s}^{-1}$ & $-0.23^{*}$ & 0.01 & $-0.27^{*}$ & 0.03 & $-0.27^{*}$ & -0.08 \\
\hline Dorsiflexor isokinetic $180^{\circ} . \mathrm{s}^{-1}$ & -0.14 & 0.09 & -0.21 & 0.11 & -0.21 & -0.07 \\
\hline Knee extensor isometric strength & -0.28 & $-0.32 *$ & $-0.38 *$ & $-0.35^{*}$ & -0.34 & $-0.4 I^{*}$ \\
\hline Knee extensor isokinetic $60^{\circ} . \mathrm{s}^{-1}$ & $-0.22 *$ & $-0.27^{* *}$ & $-0.22 *$ & $-0.37 * *$ & $-0.27^{*}$ & $-0.23^{*}$ \\
\hline Knee extensor isokinetic $180^{\circ} . \mathrm{s}^{-1}$ & $-0.21^{*}$ & -0.01 & -0.03 & $-0.35^{* *}$ & 0.08 & $-0.21^{*}$ \\
\hline Knee flexor isometric strength & -0.09 & -0.04 & -0.10 & -0.11 & 0.04 & -0.17 \\
\hline Knee flexor isokinetic $60^{\circ} . \mathrm{s}^{-1}$ & -0.11 & $-0.21^{*}$ & -0.17 & $-0.36 * *$ & -0.02 & $-0.32 * *$ \\
\hline Knee flexor isokinetic $180^{\circ} . \mathrm{s}^{-1}$ & 0.09 & $-0.20 *$ & -0.17 & $-0.50 * *$ & 0.06 & $-0.34 * *$ \\
\hline Hip extensor isokinetic $60^{\circ} . \mathrm{s}^{-1}$ & -0.36 & -0.02 & -0.31 & -0.18 & -0.12 & -0.15 \\
\hline Hip extensor isokinetic $180^{\circ} . \mathrm{s}^{-1}$ & -0.34 & -0.34 & -0.29 & -0.25 & -0.20 & -0.23 \\
\hline Hip flexor isokinetic $60^{\circ} . \mathrm{s}^{-1}$ & 0.08 & 0.00 & -0.16 & -0.24 & -0.08 & -0.14 \\
\hline Hip flexor isokinetic $180^{\circ} . \mathrm{s}^{-1}$ & 0.19 & -0.19 & -0.08 & -0.04 & 0.16 & -0.02 \\
\hline
\end{tabular}

Notes: OLD: $60-70$ years old; VOD: 7I-86 years old. ${ }^{*} \mathrm{p}<0.05,{ }^{* *} \mathrm{p}<0.01$.

Abbreviations: 5STS, five-times-sit-to-stand; TUG, time up and go; W6M, 6m-walk test. 
Table 3 Linear Multiple Regression Analysis to Predict TUG Performance Using Strength Measurements (HS, Isokinetic Torque of the Ankle and Knee Joints) for All Participants (ALL), Old Adults (OLD) and Very Old Adults (VOD)

\begin{tabular}{|c|c|c|c|c|c|c|}
\hline & & Explanatory Variable & $\begin{array}{l}\text { Coefficient } \\
\text { (STD Error) }\end{array}$ & 95\% Confidence Interval & T Statistics & $P$ value \\
\hline \multirow[t]{21}{*}{$60^{\circ} \cdot s^{-1}$} & \multirow[t]{7}{*}{ ALL } & \multicolumn{5}{|c|}{$\left(n=148 ; R^{2}=0.150 ; R^{2}\right.$ adjusted $\left.=0.120\right)$} \\
\hline & & Constant & 11.975 (1.318) & $(9.37,14.58)$ & 9.08 & $<0.01$ \\
\hline & & $\mathrm{HS}$ & $0.026(0.047)$ & $(-0.067,0.12)$ & 0.55 & 0.58 \\
\hline & & Knee ext. $60^{\circ} . \mathrm{s}^{-1}$ & $-0.012(0.015)$ & $(-0.041,0.018)$ & -0.79 & 0.43 \\
\hline & & Knee flex $60^{\circ} \cdot \mathrm{s}^{-1}$ & $-0.028(0.022)$ & $(-0.072,0.017)$ & -1.23 & 0.22 \\
\hline & & Plantar flex. $60^{\circ} . \mathrm{s}^{-1}$ & $-0.05 \mathrm{I}(0.02 \mathrm{I})$ & $(-0.092,-0.011)$ & -2.50 & $0.01 *$ \\
\hline & & Dorsi flex. $60^{\circ} . \mathrm{s}^{-1}$ & $0.035(0.064)$ & $(-0.091,0.162)$ & 0.550 & 0.58 \\
\hline & \multirow[t]{7}{*}{ OLD } & \multicolumn{5}{|c|}{$\left(n=72 ; R^{2}=0.176 ; R^{2}\right.$ adjusted $\left.=0.114\right)$} \\
\hline & & Constant & $10.37 \mid(1.009)$ & $(8.356,12.386)$ & 10.27 & $<0.01$ \\
\hline & & $\mathrm{HS}$ & $0.034(0.03 I)$ & $(-0.028,0.097)$ & 1.10 & 0.27 \\
\hline & & Knee ext. $60^{\circ} . \mathrm{s}^{-1}$ & $-0.009(0.010)$ & $(-0.029,0.012)$ & -0.85 & 0.40 \\
\hline & & Knee flex. $60^{\circ} \cdot \mathrm{s}^{-1}$ & $0.015(0.015)$ & $(-0.0125,0.045)$ & 0.97 & 0.33 \\
\hline & & Plantar flex. $60^{\circ} . \mathrm{s}^{-1}$ & $-0.029(0.013)$ & $(-0.055,-0.003)$ & -2.22 & $0.03 *$ \\
\hline & & Dorsi flex. $60^{\circ} . \mathrm{s}^{-1}$ & $-0.075(0.047)$ & $(-0.0169,0.019)$ & -1.59 & 0.12 \\
\hline & \multirow[t]{7}{*}{ VOD } & \multicolumn{5}{|c|}{$\left(n=76 ; R^{2}=0.191 ; R^{2}\right.$ adjusted $\left.=0.133\right)$} \\
\hline & & Constant & $12.308(2.210)$ & $(7.899,16.716)$ & 5.57 & $<0.01$ \\
\hline & & HS & $0.036(0.091)$ & $(-0.146,0.217)$ & 0.39 & 0.69 \\
\hline & & Knee ext. $60^{\circ} . s^{-1}$ & $-0.005(0.027)$ & $(-0,059,0.048)$ & -0.19 & 0.85 \\
\hline & & Knee flex. $60^{\circ} . \mathrm{s}^{-1}$ & $-0.05 I(0.043)$ & $(-0.136,0.033)$ & -1.21 & 0.23 \\
\hline & & Plantar flex. $60^{\circ} . \mathrm{s}^{-1}$ & $-0.078(0.04 I)$ & $(-0.160,0.004)$ & -1.91 & $0.06 *$ \\
\hline & & Dorsi flex. $60^{\circ} . \mathrm{s}^{-1}$ & $0.106(0.110)$ & $(-0.115,0.326)$ & 0.95 & 0.34 \\
\hline \multirow[t]{21}{*}{$180^{\circ} . s^{-1}$} & \multirow[t]{7}{*}{ ALL } & \multicolumn{5}{|c|}{$\left(n=148 ; R^{2}=0.158 ; R^{2}\right.$ adjusted $\left.=0.129\right)$} \\
\hline & & Constant & 11.851 (1.213) & $(9.453,14.248)$ & 9.77 & $<0.01$ \\
\hline & & HS & $0.010(0.048)$ & $(-0.086,0.106)$ & 0.20 & 0.84 \\
\hline & & Knee ext. $180^{\circ} . s^{-1}$ & $0.015(0.015)$ & $(-0.014,0.045)$ & 1.03 & 0.30 \\
\hline & & Knee flex. $180^{\circ} . \mathrm{s}^{-1}$ & $-0.091(0.056)$ & $(-0.144,0.038)$ & -3.37 & $<0.01 *$ \\
\hline & & Plantar flex. $180^{\circ} . \mathrm{s}^{-1}$ & $-0.032(0.023)$ & $(-0.076,-0.013)$ & $-1.4 \mid$ & 0.16 \\
\hline & & Dorsi flex. $180^{\circ} . \mathrm{s}^{-1}$ & $0.016(0.056)$ & $(-0.095,0.128)$ & 0.29 & 0.77 \\
\hline & \multirow[t]{7}{*}{ OLD } & \multicolumn{5}{|c|}{$\left(n=72 ; R^{2}=0.110 ; R^{2}\right.$ adjusted $\left.=0.042\right)$} \\
\hline & & Constant & $9.669(0.950)$ & $(7.772$, II.566) & 10.17 & $<0.01$ \\
\hline & & HS & $0.017(0.034)$ & $(-0.052,0.086)$ & 0.49 & 0.63 \\
\hline & & Knee ext. $180^{\circ} . \mathrm{s}^{-1}$ & $0.011(0.010)$ & $(-0.009,0.030)$ & 1.11 & 0.27 \\
\hline & & Knee flex. $180^{\circ} . \mathrm{s}^{-1}$ & $-0.013(0.020)$ & $(-0.052,0.027)$ & -0.64 & 0.52 \\
\hline & & Plantar flex. $180^{\circ} . \mathrm{s}^{-1}$ & $-0.021(0.014)$ & $(-0.049,0.007)$ & $-|.5|$ & 0.14 \\
\hline & & Dorsi flex. $180^{\circ} . \mathrm{s}^{-1}$ & $-0.074(0.04 \mathrm{I})$ & $(-0.0155,0.007)$ & -1.82 & 0.07 \\
\hline & \multirow[t]{7}{*}{ VOD } & \multicolumn{5}{|c|}{$\left(n=76 ; R^{2}=0.232 ; R^{2}\right.$ adjusted $\left.=0.178\right)$} \\
\hline & & Constant & 12.143 (2.098) & $(7.959,16.327)$ & 5.78 & $<0.01$ \\
\hline & & HS & $-0.008(0.090)$ & $(-0.188,0.172)$ & -0.09 & 0.93 \\
\hline & & Knee ext. $180^{\circ} . \mathrm{s}^{-1}$ & $0.028(0.032)$ & $(-0.035,0.092)$ & 0.89 & 0.38 \\
\hline & & Knee flex. $180^{\circ} . \mathrm{s}^{-1}$ & $-0.142(0.050)$ & $(-0.242,-0.043)$ & -2.85 & $<0.01 *$ \\
\hline & & Plantar flex. $180^{\circ} . \mathrm{s}^{-1}$ & $-0.035(0.051)$ & $(-0.137,0.066)$ & -0.70 & 049 \\
\hline & & Dorsi flex. $180^{\circ} . \mathrm{s}^{-1}$ & $0.121(0.102)$ & $(-0.083,0.324)$ & 1.18 & 0.24 \\
\hline
\end{tabular}

Note:*Indicates significant differences. 
HS tests (reliable, valid, noninvasive, inexpensive measurement, etc.) the magnitude of the correlation coefficients ranged from negligible to low and explained only a minor fraction of the variance of the lower limb strength. There are arguments that HS is of limited use since it does not provide a sensitive measure of strength after a period of training, although it has been widely used as a primary outcome in exercise-training interventions. ${ }^{41}$ It may be the case that HS provides an accurate strength measure for the upper limbs, more specifically for the muscles involved in grip or pinch demands, but of little contribution to explaining the strength of other muscle sites. Therefore, the hypothesis that HS and the performance of isometric and isokinetic strength present small correlations was accepted.

Muscle strength is essential in many daily-life activities that allow us to walk, stand from a chair, climb stairs and perform a paramount number of movements. Many researchers have used the HS as an overall strength measure $^{4,35}$ and a predictor of disability in very old adults. $^{42}$ Indeed, activities of daily living (eg, taking a bath, eating, dressing up) have been correlated to $\mathrm{HS}^{42}$ as the use of upper limbs is far more required than in the functional tests used in the present study. Thus, replacing tests designed to determine the strength and the performance of the lower limbs by HS measures may neglect the specificity of the motor tasks involved in functional tests. Some studies have demonstrated such a negligibility, low, or no correlation between HS and functional tests. ${ }^{40,43}$ Therefore, HS may be only considered assessing upper body functional tests, due to it fails to explain changes in lower limb strength performance and functional tests.

On the other hand, the variance of lower limb functional tests, such as 5STS, TUG and W6M tests, can be partially explained by the strength of the lower limbs. Previous analyses have presented a low correlation between functional capacity and isometric knee extension strength. ${ }^{44}$ The isometric and dynamic lower limb torque presented low to moderate correlations with functional tests. It seems that strength measures can not fully explain functional performance as it also relies on other characteristics such as muscle coordination, agility, flexibility and balance. ${ }^{45}$ Besides, physical capacity and the performance to perform activities of daily living may not be remarkably influenced when strength is above to a certain minimum threshold. ${ }^{46}$ McGrath and colleagues ${ }^{47}$ have shown that decreased HS was related to increased odds for several daily life activities, which were associated with a higher hazard for mortality in older adults.
It is interesting to note a large number of significant correlations between the strength of the plantar flexor muscles and the functional tests in comparison to knee and hip joint muscles. For instance, there was no significant correlation between hip joint strength and functional tests. It is necessary to consider that most functional tests selected in the present study included gait, which has been considered to change in the presence of hip and knee extensor muscle weakness. ${ }^{48}$ In addition, it has been demonstrated that the plantar flexor muscles are primer movers and more demanded (ie, present a large mechanical demand) than the hip muscles. ${ }^{49}$ The contribution of the plantar flexor muscles is advantageous to generate a large propulsive impulse at the end of the stance phase, ${ }^{50}$ which increases the upward forces to rise and rotate the hip to improve pelvic gait. ${ }^{17}$ Therefore, the strength of the plantar flexor muscles seemed to have a more prominent role during the gait and may partially explain the correlations between strength and functional tests. Indeed, the regression analysis revealed that the greater the peak torque of the ankle muscles (measured at $60^{\circ} . \mathrm{s}^{-1}$ ) the shorter was the TUG time.

On the other hand, when the speed of the force tests was set at $180^{\circ} . \mathrm{s}^{-1}$, the knee flexor muscles presented significance to explain TUG performance. Despite the significance level, only a small amount of the variance of the knee flexors peak torque $(9.0 \%$ and $14 \%$ for ALL and VOD groups, respectively) explains the functional outcome in the TUG test. This is in line with the idea that the rate of torque development of the knee flexors plays an important role when the walking speed increases. ${ }^{51}$ Therefore, it seems that the test speed is relevant as walking as fast as possible demands more fast and powerful actions of the muscles than strength itself. ${ }^{51}$

The W6M and TUG functional tests, selected in the present study, demonstrated a large dependence on the participants' ability to walk at faster speeds. It has been shown that gait depends less on soleus muscle activation to push off at faster walking speeds, ${ }^{52}$ which is not a common characteristic among VOD individuals. Therefore, it may be assumed that very old adults rely more on the ankle muscles than their younger counterparts, as declines in muscle strength are likely to present a more pronounced impact on the long-living senescence. This may explain why the VOD group showed a larger number of correlations between the ankle strength measures and functional capacity than the OLD group.

The multiple regression revealed that force, as a standalone measure (ie, peak torque or HS), does not explain 
the TUG performance, as it encompasses a plethora of complex components (eg, balance, coordination, agility, etc.) that are not fully captured while assessing a binary single-joint movement (ie, flexion/extension). In this context, it is not surprising that HS - a static measure performed in an unrelated body limb - was not able to explain functional capacity, irrespective of the participants' age. Therefore, the hypothesis that HS is unable to explain functional capacity was accepted. On the other hand, the hypothesis that HS and strength measures and functional performance are influenced by age was not confirmed.

This study has some limitations to be considered while interpreting the results. First, the reduced period of familiarization (2-3 sessions on different days) may be not sufficient to reduce learning effects. Second, measurements performed in one lower limb may be influenced by the measurements obtained from both limbs. The good health status of our participants may have influenced our results and limit comparisons across studies that have assessed older adults with several comorbidities (eg, cancer, diabetes and cardiovascular diseases), as sedentarism is a coadjutant factor. Finally, no body mass correction was performed. As a general rule, correcting strength by body mass is performed to take into account differences in the amount of muscle mass, which is not the case as the fat content (infiltrated fat) is more likely to influence performance than muscle mass itself. In addition, differences in the body mass between groups were almost negligible $(2.1 \mathrm{~kg} ; \sim 3.0 \%)$.

\section{Conclusions}

In the present study, most correlations of HS with strength and functional tests were non-significant and the magnitudes ranged from negligible to low and, in a few cases, moderate. Although several studies have used the HS as a practical and straightforward measure to determine overall strength, and as a useful tool for screening large samples to predict falls and functional capacity in the dwelling-elderly women community, our data do not support such findings. It may be related to the use of the small number of participants analyzed in other studies. Furthermore, the correlation of HS and lower limb strength (isometric and isokinetic) with functional capacity was not influenced by age.

\section{Data Sharing Statement}

Data are available upon request.

\section{Ethics Approval}

All studies were approved by the Dom Bosco University Ethical Committee and were in accordance with the Declaration of Helsinki.

\section{Consent to Participate}

All participants signed an informed consent form.

\section{Consent for Publication}

All authors are aware that if accepted the Journal will have all rights regarding the publication.

\section{Acknowledgments}

The authors thank all researchers (Anna R. S. Gomes, Audrin S. Vojciechowski, Elisângela V. Rodrigues, Luiza H. Gallo, Paulo C. B. Bento, Sabrine N. Costa, Simone Biesek and Ryelen N. S. A. Garcia) who provided the data from their studies. All these studies were financed in part by the Coordenação de Aperfeiçoamento de Pessoal de Nível Superior - Brasil (CAPES) - Finance Code 001 - PGPTA project.

\section{Author Contributions}

All authors contributed to data analysis, drafting or revising the article, gave final approval of the version to be published, and agree to be accountable for all aspects of the work.

\section{Funding}

This study derives from a number of studies in which some of them were funded by CAPES (Coordenação de Aperfeiçoamento de Pessoal de Nível Superior - Brazil).

\section{Disclosure}

The authors report no conflicts of interest in this work.

\section{References}

1. Briggs AM, Cross MJ, Hoy DG, et al. Musculoskeletal health conditions represent a global threat to healthy aging: a report for the 2015 world health organization world report on ageing and health. Gerontologist. 2016;56(Suppl 2):S243-55. doi:10.1093/geront/gnw002

2. Björk S, Juthberg C, Lindkvist M, et al. Exploring the prevalence and variance of cognitive impairment, pain, neuropsychiatric symptoms and ADL dependency among persons living in nursing homes; a cross-sectional study. BMC Geriatr. 2016;16(1):154. doi:10.1186/s12877-016-0328-9

3. Martien S, Delecluse C, Boen F, et al. Is knee extension strength a better predictor of functional performance than handgrip strength among older adults in three different settings? Arch Gerontol Geriatr. 2015;60(2):252-258. doi:10.1016/j.archger.2014.11.010

4. Buckley C, Stokes M, Samuel D. Muscle strength, functional endurance, and health-related quality of life in active older female golfers. Aging Clin Exp Res. 2017. doi:10.1007/s40520-017-0842-4 
5. Mathiowetz V. Comparison of Rolyan and Jamar dynamometers for measuring grip strength. Occup Ther Int. 2002;9(3):201-209. doi:10.1002/oti.165

6. Peolsson RH, Birgitta $\mathrm{Ob} \mathrm{A}$. Intra- and inter-tester reliability and reference values for hand strength. J Rehabil Med. 2001;33(1):36-41. doi:10.1080/165019701300006524

7. Schaubert KL, Bohannon RW. Reliability and validity of three strength measures obtained from community-dwelling elderly persons. J Strength Cond Res. 2005;19(3):717. doi:10.1519/R-15954.1

8. Everett PW, Sills FD. The relationship of grip strength to stature, somatotype components, and anthropometric measurements of the hand. Res Quart Am Assoc Health Phys Educ Recreat. 1952;23 (2):161-166. doi:10.1080/10671188.1952.10761971

9. Frederiksen H, Hjelmborg J, Mortensen J, Mcgue M, Vaupel JW, Christensen K. Age trajectories of grip strength: cross-sectional and longitudinal data among 8,342 danes aged 46 to 102. Ann Epidemiol. 2006;16(7):554-562. doi:10.1016/j.annepidem.2005.10.006

10. Barbosa JF, Deshpande N, Gomez Monters J, et al. Handgrip strength points associated with slowness for the identification of clinically relevant weakness may not be universal. Gerontologist. 2015;55 (Suppl_2):193. doi:10.1093/geront/gnv550.29

11. Bohannon RW. Hand-grip dynamometry predicts future outcomes in aging adults. J Geriatric Phys Ther. 2008;31(1):3-10. doi:10.1519/ 00139143-200831010-00002

12. Kemp GJ, Birrell F, Clegg PD, et al. Developing a toolkit for the assessment and monitoring of musculoskeletal ageing. Age Ageing. 2018;47(suppl_4):1-19. doi:10.1093/ageing/afy143

13. Sargent-Cox KA, Butterworth P, Anstey KJ. Role of physical activity in the relationship between mastery and functional health Gerontologist. 2015;55(1):120-131. doi:10.1093/geront/gnu042

14. Bohannon RW. Hand-held compared with isokinetic dynamometry for measurement of static knee extension torque (Parallel reliability of dynamometers). Clin Phys Physiolog Measure. 1990;11 (3):217-222. doi:10.1088/0143-0815/11/3/004

15. Li RC, Jasiewicz JM, Middleton J, et al. The development, validity, and reliability of a manual muscle testing device with integrated limb position sensors. Arch Phys Med Rehabil. 2006;87(3):411-417. doi:10.1016/j.apmr.2005.11.011

16. Martin HJ, Yule V, Syddall HE, Dennison EM, Cooper C, Aihie Sayer A. Is hand-held dynamometry useful for the measurement of quadriceps strength in older people? A comparison with the gold standard biodex dynamometry. Gerontology. 2006;52(3):154-159. doi:10.1159/000091824

17. Casey KD, Lee LW, Collins JJ, Riley PO, Lipsitz LA. Reduced hip extension during walking: healthy elderly and fallers versus young adults. Arch Phys Med Rehabil. 2001;82(1):26-30. doi:10.1053/ apmr.2001.18584

18. Murphy AJ, Wilson GJ. Poor correlations between isometric tests and dynamic performance: relationship to muscle activation. Eur J Appl Physiol Occup Physiol. 1996;73(3-4):353-357. doi:10.1007/ BF02425498

19. Moreira NB, Rodacki ALF, Pereira G, Bento PCB. Does functional capacity, fall risk awareness and physical activity level predict falls in older adults in different age groups? Arch Gerontol Geriatr. 2018;77. doi:10.1016/j.archger.2018.04.002

20. Sullivan KM, Dean A. OpenEpi: a web-based epidemiologic and statistical calculator for public health. Public Health Rep. 2009;124 (June):471-474. doi:10.2307/25682255

21. Folstein MF, Folstein SE, McHugh PR. 'Mini-mental state'. A practical method for grading the cognitive state of patients for the clinician. J Psychiatr Res. 1975;12(3):189-198. doi:10.1016/ 0022-3956(75)90026-6

22. Roberts HC, Denison HJ, Martin HJ, et al. A review of the measurement of grip strength in clinical and epidemiological studies: towards a standardised approach. Age Ageing. 2011;40(4):423-429. doi:10. 1093/ageing/afr051
23. Wang CY, Chen LY. Grip strength in older adults: test-retest reliability and cutoff for subjective weakness of using the hands in heavy tasks. Arch Phys Med Rehabil. 2010;91(11):1747-1751. doi:10.1016/ j.apmr.2010.07.225

24. Junior L, Marcos R, Netto WA, et al. Concurrent validity of handheld dynamometer measurements for scapular protraction strength. Braz J Phys Ther. 2018;22(4):328-335. doi:10.1016/j.bjpt.2018.08.002

25. Podsiadlo D, Richardson S. The timed 'up \& go': a test of basic functional mobility for frail elderly persons. $J$ Am Geriatr Soc. 1991;39(2):142-148. doi:10.1111/j.1532-5415.1991.tb01616.x

26. Hasegawa R, Islam MM, Lee SC, Koizumi D, Rogers ME, Takeshima N. Threshold of lower body muscular strength necessary to perform ADL independently in community-dwelling older adults. Clin Rehabil. 2008;22(10-11):902-910. doi:10.1177/0269215508094713

27. Webber SC, Porter MM. Reliability of ankle isometric, isotonic, and isokinetic strength and power testing in older women. Phys Ther. 2010;90(8):1165-1175. doi:10.2522/ptj.20090394

28. Whitney SL, Wrisley DM, Marchetti GF, Gee MA, Redfern MS, Furman JM. Clinical measurement of sit-to-stand performance in people with balance disorders: validity of data for the five-times-sitto-stand test. Phys Ther. 2005;85(10):1034-1045. doi:10.1191/ 026921598673062266

29. Rogers ME, Rogers NL, Takeshima N, Islam MM. Methods to assess and improve the physical parameters associated with fall risk in older adults. Prev Med. 2003;36(3):255-264. doi:10.1016/S0091-7435(02) 00028-2

30. Steffen TM, Hacker T, Mollinger L. Age- and gender-related test performance in community-dwelling elderly people: six-minute walk test, berg balance scale, timed up \& go test, and gait speeds. Phys Ther. 2002;82(2):128-137. doi:10.1093/ptj/82.2.128

31. Bohannon RW. Reference values for the five-repetition sit-to-stand test: a descriptive meta-analysis of data from elders. Percept Mot Skills. 2006;103(1):215-222. doi:10.2466/PMS.103.5.215-222

32. Witz K, Hinkle DE, Wiersma W, Jurs SG. Applied statistics for the behavioral sciences. J Educ Stat. 1990;15(1):84. doi:10.2307/ 1164825

33. Benjamini Y, Hochberg Y. Controlling the false discovery rate a practical and powerful approach to multiple testing. J R Stat Soc Ser B. 1995;57(1):289-300.

34. Schlüssel MM, Antonio Dos Anjos L, Leite de Vasconcellos MT, Kac G. Reference values of handgrip dynamometry of healthy adults: a population-based study. Clin Nutri. 2008;27(4):601-607. doi:10.1016/ j.clnu.2008.04.004

35. Bohannon RW, Magasi SR, Bubela DJ, Wang Y-C, Gershon RC. Grip and knee extension muscle strength reflect a common construct among adults. Muscle Nerve. 2012;46(4):555-558. doi:10.1002/mus.23350

36. Kallman DA, Plato CC, Tobin JD. The role of muscle loss in the age-related decline of grip strength: cross-sectional and longitudinal perspectives. J Gerontol. 1990;45(3):M82-88. doi:10.1093/geronj/ 45.3.M82

37. Tieland M, Verdijk LB, De Groot LCPGM, Van Loon LJC. Handgrip strength does not represent an appropriate measure to evaluate changes in muscle strength during an exercise intervention program in frail older people. Int J Sport Nutr Exerc Metab. 2015;25 (1):27-36. doi:10.1123/ijsnem.2013-0123

38. Norman K, Stobäus N, Smoliner C, et al. Determinants of hand grip strength, knee extension strength and functional status in cancer patients. Clin Nutri. 2010;29(5):586-591. doi:10.1016/j.clnu.2010.02.007

39. Felicio DC, Pereira DS, Assumpção AM, et al. Poor correlation between handgrip strength and isokinetic performance of knee flexor and extensor muscles in community-dwelling elderly women. Geriatr Gerontol Int. 2014;14(1):185-189. doi:10.1111/ggi.12077

40. Alonso AC, Ribeiro SM, Silva Luna NM, et al. Association between handgrip strength, balance, and knee flexion/extension strength in older adults. PLoS One. 2018;13(6):1-9. doi:10.1371/journal. pone. 0198185 
41. Straight CR, Dorfman LR, Cottell KE, Krol JM, Lofgren IE, Delmonico MJ. Effects of resistance training and dietary changes on physical function and body composition in overweight and obese older adults. J Phys Act Health. 2012;9(6):875-883. doi:10.1123/jpah.9.6.875

42. Taekema DG, Gussekloo J, Maier AB, Westendorp RGJ, de Craen AJM. Handgrip strength as a predictor of functional, psychological and social health. A prospective population-based study among the oldest old. Age Ageing. 2010;39(3):331-337. doi:10. 1093/ageing/afq022

43. Dulac MC, Carvalho LP, Aubertin-Leheudre M. Functional capacity depends on lower limb muscle strength rather than on abdominal obesity in active postmenopausal women. Menopause. 2018;25 (2):176-181. doi:10.1097/GME.0000000000000970

44. Barbat-Artigas S, Rolland Y, Cesari M, Abellan van Kan G, Vellas B, Aubertin-Leheudre M. Clinical relevance of different muscle strength indexes and functional impairment in women aged 75 years and older. J Gerontol a Biol Sci Med Sci. 2013;68(7):811-819. doi:10.1093/gerona/gls254

45. Rolland Y, Czerwinski S, Abellan Van Kan G, et al. Sarcopenia: its assessment, etiology, pathogenesis, consequences and future perspectives. J Nutr Health Aging. 2008;12(7):433-450. doi:10. 1007/BF02982704
46. Rantanen T. Muscle strength, disability and mortality. Scand J Med Sci Sports. 2003;13(1):3-8. doi:10.1034/j.1600-0838.2003.00298.x

47. McGrath RP, Kraemer WJ, Snih SA, Peterson MD. Handgrip strength and health in aging adults. Sports Med. 2018;48(9):1993-2000. doi:10.1007/s40279-018-0952-y

48. Krogt MM, Delp SL, Schwartz MH. How robust is human gait to muscle weakness? Gait Posture. 2012;36(1):113-119. doi:10.1016/j. gaitpost.2012.01.017

49. Requião LF, Nadeau S, Milot MH, Gravel D, Bourbonnais D, Gagnon D. Quantification of level of effort at the plantar flexors and hip extensors and flexor muscles in healthy subjects walking at different cadences. $J$ Electromyography Kinesiol. 2005;15 (4):393-405. doi:10.1016/j.jelekin.2004.12.004

50. Kuo AD. Energetics of actively powered locomotion using the simplest walking model. J Biomech Eng. 2001;124(1):113. doi:10.1115/ 1.1427703

51. Neptune RR, Sasaki K, Kautz SA. The effect of walking speed on muscle function and mechanical energetics. Gait Posture. 2008;28 (1):135-143. doi:10.1016/j.gaitpost.2007.11.004

52. Schmitz A, Silder A, Heiderscheit B, Mahoney J, Thelen DG. Differences in lower-extremity muscular activation during walking between healthy older and young adults. J Electromyography Kinesiol. 2009;19(6):1085-1091. doi:10.1016/j.jelekin.2008.10.008
Clinical Interventions in Aging

\section{Publish your work in this journal}

Clinical Interventions in Aging is an international, peer-reviewed journal focusing on evidence-based reports on the value or lack thereof of treatments intended to prevent or delay the onset of maladaptive correlates of aging in human beings. This journal is indexed on PubMed Central, MedLine, CAS, Scopus and the Elsevier

\section{Dovepress}

Bibliographic databases. The manuscript management system is completely online and includes a very quick and fair peer-review system, which is all easy to use. Visit http://www.dovepress.com/ testimonials.php to read real quotes from published authors. 